\title{
Competitiveness, EMU and Cohesion Experiences in the Past (2000-2013); Assessment of the Present (2014-2020) and Lessons for the Future (2020 and Beyond)
}

\begin{abstract}
The European Union has adopted several strategies to cope with a set of inter-related problems. The best known is the Europe 2020 strategy with its focus on smart, sustainable and inclusive growth. Another is fostering balanced macro growth via a strengthening of the EMU. Finally the cohesion policy has to cope with spatial unbalances. The objective of this paper is to highlight the main issues in three policy fields: competitiveness, EMU and cohesion. ${ }^{1}$ Two scenarios for post 2020 development are described, which show the need for further strengthening of EU policies and of the quality of government at all levels.
\end{abstract}

Keywords: European Union, Competitiveness, EMU, Cohesion, Scenarios beyond 2020 JEL: E52, O14, O33, R11,12

\section{Introduction}

This paper focuses on the spatial dimension of the conditions for growth. We distinguish between three large geographical areas of the EU; North, South and East, paying particular attention to the East and Visegrad four countries. ${ }^{2}$

For each policy field, we describe the issues and the relevant policy solutions for two periods: the recent past (2000-2013) and the present (2014-2020). 
In the last section of the paper two future alternative scenarios are posed; one pessimistic, and the other optimistic. This juxtaposition of possible outcomes highlights the challenges ahead; notably, the need to further strengthen the European architecture and quality of governments on national and regional levels.

A short conclusion will round off the paper.

\section{Competitiveness}

\section{Past: 2000-2013}

Competitiveness is defined as the ability of countries, regions, cities or social groups to generate (while being exposed to external competition) relatively high income and employment levels. We distinguish the main drivers of competitiveness (and hence growth): ${ }^{3}$

- industrial structure (specialization in high-value-added activities, new products and services; clusters of related activities);

- innovation (research and development institutes; knowledge-based firms);

- accessibility (telecommunication networks; transport infrastructure, urban services);

- environmental quality (environmental damage can be a barrier to development);

- human resources (employment rate, educational level, training and teaching facilities, adaptability of the labor force, entrepreneurial talent); and

- good governance (the rule of law; reliability and effectiveness of public sector services, absence of corruption).

For some time, an EU priority has been to improve competitiveness, as reflected by the Lisbon Strategy. In 2010, this goal was articulated in the Europe 2020 Strategy as smart, sustainable, inclusive growth. The competitiveness drivers listed above can easily be related to these three main Europe 2020 objectives. Smart growth is largely determined by developing the first three of these drivers; sustainable growth by the fourth driver; and inclusive growth by the fifth. The last driver cited - institutional and administrative system quality - is a precondition for effectiveness of all other drivers.

The various components of competitiveness have been measured on the national, regional and urban level and amalgamated into one composite indictor (Figure1).

This indicator reveals the following fairly simple geographical structure; Northern countries are to the right; Southern and Eastern countries are to the left, mostly Eastern countries (and Greece) are in the extreme left, and the V4 countries are in the middle of figure 1 (together with a number of the more developed countries from the South). And the capital cities of each country occupy the best position. ${ }^{4}$

There are no comparable figures available for describing the past development of the patterns of competitiveness on the lower spatial levels. However, partial data suggest that 
over the past decade Eastern countries have made significant gains; and so have most of their regions. By contrast, Southern countries (and, in particular their 'problem' regions) have suffered considerable losses, which have been set in long before the crisis.

FIGURE1. Competitiveness index by member state, region and capital city (2013)

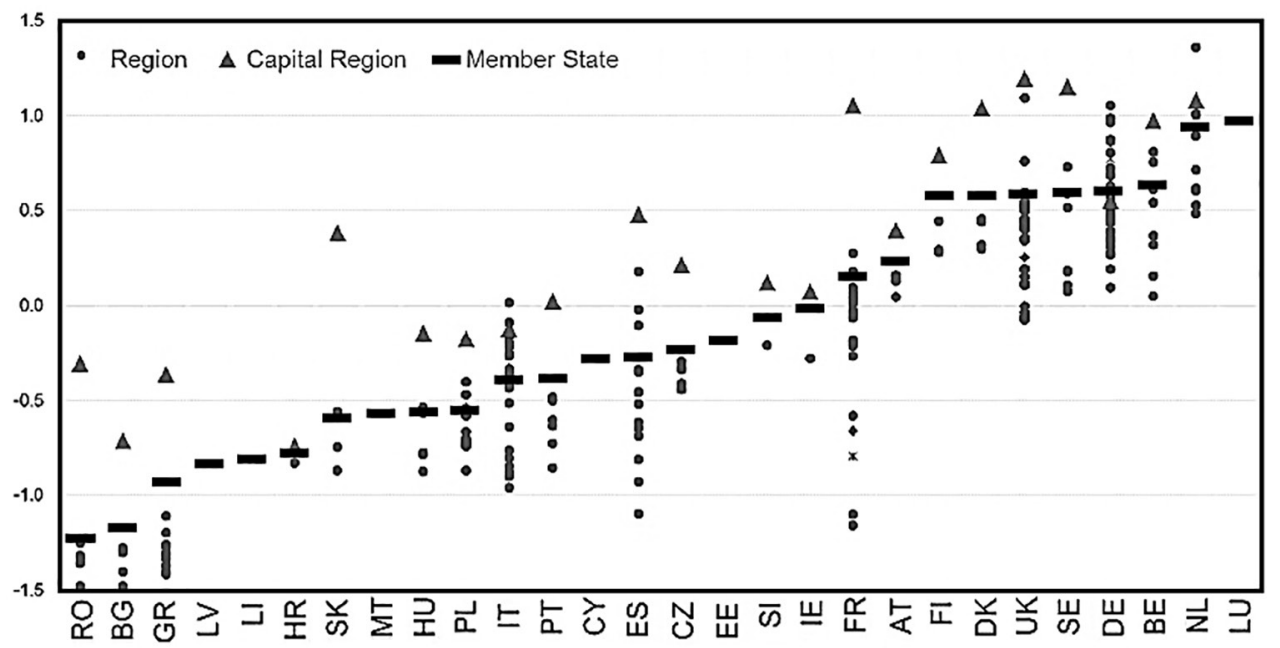

S o u r c e: adapted from: Annoni and Dijkstra [2013].

\section{Present: 2014-2020}

The national dimension of competitiveness has been studied by the European Commission over time. Since 1997, the EC has published an annual Competitiveness Report, which quantitatively assesses the development of the main determinants of competitiveness of EU industries by country. These reports show that differences between EU countries are large and rather persistent. Moreover, similar patterns for the indicators of the various drivers of competitiveness are discerned. The latest report underscores the importance of the 'availability of adequate funding' and 'good government' to the growth of firms, and advocated policy reforms to reduce barriers to competitiveness. ${ }^{5}$

Although systematic information for the regional dimension of competitiveness is not available, regional competiveness is a focus of the Europe 2020 targets. For those targets that correspond to a competiveness driver, the gap between current conditions and aspirational goals has been assessed, and relevant data amalgamated in a comprehensive weighted index. These figures show that, by region, the largest problems are posed in the southern regions of Portugal, Spain, Italy, and portions of the Balkans. These results are not new. ${ }^{6}$ 
Within countries, the main urban centers tend to outperform all other regions. This suggests that in countries where the rift between the two categories is particularly deep, specific efforts will be needed to close the gap between first tier cities and other regions. ${ }^{7}$

\section{EMU}

\section{Past: 2000-2013}

The EMU started in 2000. However, not all EU member states participated in it. Some could not join because they were not ready, and others did not want to join because they thought that participation would not benefit them. Notably the UK and Denmark negotiated an opt-out from the EMU. Membership in the EMU does not coincide with the divisions in the large geographical areas that we have adopted for this study. In the North one sees that not all countries participate (i.e., the UK). In the South, all countries of that group did participate. In the East, only a minority of mainly smaller member states participate in the EMU.

The EMU has such positive effects as greater macro-economic stability and a lowering of interest rates. However, it has also had some negative effects. The EMU permitted Southern European countries to borrow cheaply and invest in unproductive ventures. When the financial markets were in crisis, a number of these countries risked a sovereign default. Interlinkages between the financial sectors of different countries resulted in immediate contagion, and even well run countries were infected, resulting in an unprecedented crisis. Rescue packages for banks and austerity measures for public budgets have since been put in place in all EU countries to remedy the problems. Growing imbalances and the ensuing crisis have numerous effects, some negative, and others positive. ${ }^{8}$

Negative consequences include:

- Long-term loss of competitiveness (evident from balance of payments deterioration);

- Slack economic growth, which washed away the public's capacity to recover as tax revenues decreased;

- Increased unemployment (e.g., unemployment rates in Portugal and Spain reached high double digit figures);

- Increased wealth disparities between EU countries, erasing a decades long efforts to foster cohesion (see next section);

- Severely impaired quality of institutions and administrations in problem countries; and

- Deep mistrust between partners, undercutting European solidarity that had gradually developed over decades. 
Among the positive points to be mentioned are:

- The internal market is intact. The crisis has not shaken the 'acquis communautaire'; no country reacted nationalistically in economic terms (as has been the case in previous crises);

- Independence of ECB has been crucial;

- EMU and EU solidarity prevented the crisis from becoming even more devastating by, among other things, buffering exchange rates from undue turbulence (currency crises);

- EMU design failures have been addressed under heavy strain;

- Cohesion policy has been maintained; and

- Decisions on further integration of complementary policies have been undertaken. The economic and systemic crises of the EMU have had very different impacts on the three EU areas. In the North, countries were severely shaken but have now largely absorbed those shocks. However, policies designed to control budget deficits have slowed growth. For most countries in the South, the effects have been devastating. Decades of cohesion were eviscerated, tax bases eroded, black economic activities increased, and unemployment and poverty accentuated, along with the concomitant deterioration in the quality of governance systems. Recovery is, on average, painfully slow. The situation in the East is very different. There, the system has proven to be fairly resistant to shock waves, for both EMU and non-EMU members. Accordingly, the Eastern countries have continued to grow.

\section{Present: 2014-2020}

A deep crisis could happen due to the incomplete construction of the EMU and "the failure of Member States to empower it with strong instruments and to put sufficient effort into the processes." [Molle, 2011, p. 326]

In the recent past, quite a few systemic weaknesses of the EMU have been corrected. This was done through greater EU involvement in such areas as control of fiscal policy, banking surveillance, etc. These efforts have resulted in the creation of new devices such as the European Semester, National Stability Programs and the Excessive Imbalance Procedure. Institutionally, major changes have also been made - one example being the European Stability Mechanism. Together, these actions represent an unprecedented acceleration in the EU integration process. Some tend to overlook these achievements- perhaps because they were accomplished in a setting of turmoil, political instability, unsatisfactory compromises, and nationalist discourses. As the dust of that process is blown away, these large changes in the architecture of the European building will have become apparent. ${ }^{9}$

The main challenge for the EU now is to complete the EMU. Proposals have been made to create a so called Genuine Economic and Monetary Union (GEMU), that would add three steps to the present set-up: ${ }^{10}$

- Completion of the Banking Union;

- Mutualisation of (a part of) the public debt; and

- Creation of a Fund to deal with asymmetric economic shocks. 
There is considerable controversy about the need for these changes, the conditions necessary to make them feasible, and the precise form that each of these three measures should take. Notwithstanding these open questions, it does seem clear that all three aspects of the GEMU would have pro-cohesion effects and enhance the capacity of the weakest EU countries to return to balanced growth.

\section{Cohesion}

\section{Past: 2000-2013}

The primary objective of EU cohesion policy is the convergence of wealth levels. Table 1illustrates the evolution of the relative GDP/P levels of the large geographical groups of countries since 2000, during the pre-crisis and the crisis periods.

TABLE 1. GDP/P (index EU28 = 100), by countries' group, 2000-2020

\begin{tabular}{|l|c|c|c|c|}
\hline \multicolumn{1}{|c|}{ Region/year } & 2000 & 2007 & 2012 & 2020 \\
\hline North & 121 & 116 & 116 & 115 \\
\hline South & 105 & 102 & 95 & 90 \\
\hline East & 45 & 56 & 65 & 72 \\
\hline V4 & 53 & 61 & 70 & 77 \\
\hline EU 28 & 100 & 100 & 100 & 100 \\
\hline CoV (countries) & .51 & .46 & .42 & .34 \\
\hline
\end{tabular}

$\mathrm{PPP}=$ purchasing power parities. CoV Coefficient of variation.

S o u r c e : 2000-2012: Eurostat, National Accounts, several years; 2020: own forecast.

Table 1 shows that there are important differences between the three geographical areas. One is that throughout the presented period, the North was above average, the East was significantly below average, and the South was close to average.

Another is that in the pre-crisis period North countries were characterized by relatively low growth figures, and that continued the past trend towards convergence. Post- crisis, these countries were less severely impacted than many other EU countries, with the result that the convergence flattened off between 2007 and 2012.

The Eastern countries present the opposite picture. Their integration in the EU - and consequent institutional stabilization and increased market access - brought about high growth rates, which resulted in a strong tendency of convergence. ${ }^{11}$ This trend was not significantly impacted by the crisis; the major Eastern countries had maintained their 
monetary autonomy and were able to adapt to the new competitive and macro-economic environment. The V4 countries very much contributed to this tendency.

In the South, the data very clearly shows that this group of countries performed relatively poorly pre-crisis, losing out in wealth levels relative to the EU average. The consequence is quite dramatic; the trend towards convergence that had dominated the previous period was actually reversed. One reason for this development was that these countries had specialized in traditional industries that were very vulnerable to increased competition from developing countries (globalization) and new EU member countries. Moreover, these countries have not in time developed new competences in other industries and services. On the contrary; much of the investment went into the wrong projects. ${ }^{12}$

Eurozone membership permitted them to borrow cheaply and postpone adaptation. However, when the crisis hit the countries in this group were forced to operate very drastic restructurings, with a strong negative effect on GDP and, hence, GDP per head. This process played out with a particular strength in Greece, but also in Spain and Portugal and to a lesser extent in Italy and Ireland. Table 1 shows that effect: the index figure for this group dropped some 7 points between 2007 and 2012.

To cope with these disparities the EU has developed an elaborate cohesion policy. Its basic objectives and main systemic features have been relatively stable over time. After each enlargement, new member countries with relatively low income levels benefitted from that policy - most recently for member states in Central and Eastern Europe. The policy has been reoriented to deal with major new challenges; in the past this applied in particular to the Lisbon strategy for growth and competitiveness. ${ }^{13}$

\section{Present: 2014-2020}

Notwithstanding decades of EU and national efforts, table 1 demonstrates that disparity persists; suggesting that a continued effort is needed. Assuming that this effort is as effective in the future as it has been in the past, suppositions about the likely development of the GDP/P in the period up to 2020 can generally be made. ${ }^{14}$

In particular, the three large EU geographical zones should continue prior growth trends (see the last column of table 1), with the North stabilizing, the East converging further, and the South diverging further. The evolution of the coefficient of variation (based on individual country figures) shows that overall, the convergence trend observed in the past decade is likely to continue, mainly due to the dynamics of the East, which is very much driven by the V4.

These potential trends indicate that a significant policy effort is still needed. For the 2014-2020 period, essentially five main changes have been made in the system. ${ }^{15}$ These are:

1. Integration of cohesion policy with the objectives of strategy Europe 2020; this is to be facilitated by minimum allocations of funds for specific objectives;

2. Clear formulation of quantifiable results by beneficiaries of place specific targets, to focus solutions of specific local problem by integrated delivery on the ground; 
3. More binding relations between various government layers, in the form of partnership agreements;

4. More conditionality concerning effective policy implementation and macro-economic conditions. In order to make them effective the whole policy is integrated in the European Semester. Conditionality here means that disbursement of funds is made dependent on fulfilment of conditions; and

5. Efficiency measures: the practical rules for the delivery of the policy by the diverse Structural and Cohesion Funds (SCF) have been made uniform to decrease administrative burdens.

A combination of considerable financial resources with a very elaborate system of coordinated regulation has to lead to a mutual reinforcement of the effectiveness of the three policy domains: Europe 2020, Macro stability and cohesion. This system puts very high demands on the capacity of governments and the quality of their institutions, so a reinforcement of this systemic aspect is essential - as recently stressed in the EU's latest Cohesion report [EC 2014c].

\section{Future: Opportunities and Risks Beyond 2020}

\section{Optimistic Scenario; New Balanced Growth}

We have assumed in previous sections that the EU will use the present period (20142020) to recover from the crisis and restart growth. In this section, we assume that those efforts will lead to a new period of sustained and balanced growth.

We base this assumption on historical parallels. After the double energy crises of the 1970 s, new initiatives were taken to complete the Internal Market and to design the EMU. What sort of subjects would such a new élan cover this time? We can assume that it will involve first completion of the EMU (in terms of both design and accession of the presently non-euro area members in the East). We can next assume that this reinforced EMU will create the conditions of stability under which a new dynamism can occur.

We further assume that the EU faces with determination the main challenges of the period beyond 2020. Persistent social and environmental problems will require the continued pursuit of smart, sustainable and inclusive growth. External openness to competition from emerging market countries (that produce high technology goods and services) will force the EU to focus on competitiveness.

We assume that actions to improve competitiveness (e.g., education, quality government, innovation, etc.) are successful. This implies that: 1) the Structural Funds are effectively used to profoundly modernize the EU's production system; 2) the quality of government is improved (most of all in the countries with the highest deficiencies); and 
3) macroeconomic stability is maintained by a Genuine Economic and Monetary Union (GEMU). The consequences of this scenario, in terms of disparities, are positive. The North continues its position. The South picks up again. The East embarks on a trajectory to join the North: competitiveness is expanded to high value added goods.

\section{Pessimistic Scenarios; New Mistakes}

But the last crisis has shown that situations may occur which are not foreseen by standard models. It is therefore necessary to develop alternative scenarios, taking into account other, even 'undesirable, developments to be able to prepare for the worst. We develop in schematic form two such scenarios and discuss briefly the chances that they will materialize.

A 'Doom scenario' could develop in case the EMU (even with the latest and planned adaptations) cannot survive without a Political Union. Assuming that EU Member States are unwilling to take this last step in the integration process, the EMU will prove to have been step too far, and the EU may have to retreat to the stage of a Common Market plus. This scenario will place Europe in uncharted territory. However, history suggests that the EU, which has consistently overcome past problems (however cumbersome and unorthodox the solutions), will do so again. Indeed, the cost of breaking up is so high that one may assume the EU will have no choice but to overcome a new EMU/EPU crisis by developing new original organizational solutions to shape its future.

An alternative is the 'Mistake scenario', in which we assume that the Eastern countries fall in the same trap as the Southern countries did in the period before the crisis. It means a significant loss of competitiveness of this group of countries. The drivers of this development would be the usual 'suspects' - increased labor costs, real estate bubbles, poor government functioning (including rampant corruption), too much concentration in capital cities and a number of 'dangerous liaisons' between private and public sectors. The negative effect of these factors would likely be aggravated by aid dependency, unproductive investment and macro-economic disequilibria. In principle, the new EU policy architecture should minimize the risk that this alternative scenario develops. But the past has shown that hidden dangers may become apparent only in periods of crisis. So the scenario is not unrealistic. ${ }^{16}$

What would be the effects of this scenario? If growth figures for the Eastern countries resembled those of the South in the 2007-2012 period, a quite different cohesion picture than the one from the previous scenario emerges. Convergence between countries and groups of countries practically comes to a halt. Clearly then, a focus on all factors determining competitiveness and the correct use of cohesion money, in particular the quality of government, is essential because it is the cement that keeps the structure together. ${ }^{17}$ 


\section{Conclusion}

Severe problems persist in three policy areas (competitiveness, EMU and cohesion). For all three the situation of the North has been more or less stable; the situation of the South has dramatically deteriorated, while the situation of East has improved.

The EU has drawn a number of lessons from its mistakes of the past and has adapted its policy architecture to the challenges of the period up to 2020. These adaptations consist essentially of an increased focus on competitiveness, completion of the EMU, better focused cohesion efforts on Europe 2020 objectives, and a further integration of three main policy domains by strengthened coordination and conditionality.

We have explored the future and in particular the future of the countries of the Eastern group. Under a positive scenario improved conditions would lead to a further catching up of the East with the EU mean. Under a pessimistic scenario the new systems in place will not be sufficiently strong, causing countries in the East to replicate the past mistakes of the Southern countries.

In all cases the improvement of competitiveness, economic stability and cohesion is critically dependent on the improvement of the quality of government.

\section{Notes}

1 This division is inspired by the famous triade of arguments for policy intervention: allocation, stabilization and redistribution (equity) made by Musgrave and Musgrave (1989).

2 The North groups all countries in the North and Northwest of the EU. The South consists of the Mediterranean countries (Portugal, Spain, Italy, Greece, Malta and Cyprus). The East groups the Member States of Central and Eastern Europe. In interpreting the data, one has to bear in mind that these groups differ in size: the North has about half of the EU's population; the South and the East have each about one quarter.

3 See for clarification of the concept and its main drivers: Camagni (2002), Kitson et al. (2004), Bristow (2010) and Martin et al. (2012). The concept is used on all government levels; the EU, countries, regions and cities.

4 Of course, various EU member countries are at different stages of development. In the more advanced stages represented by the right hand group, factors like innovation are more important than at a lower stage of development (e.g., the left hand part, where the cost of production factors play a larger role). Moreover, the interdependencies of countries at different stages in development can be a stimulus for growth and reform.

5 See: EC (2014a) in particular chapter 4. The findings of the series of EC reports are corroborated by those of a similar series of studies by the World Economic Forum that place competitiveness in the Europe 2020 perspective; see e.g.: WEF (2014). 
6 See: Athanasoglou and Dijkstra (2014).

7 For cities a competitiveness divide (between Northern and Western Europe on the one hand, and Southern and Eastern Europe on the other hand) is likely to be maintained through 2025 (EIU, 2013, 19).

8 In the past, these countries could regain competitiveness by devaluing their currency; an option no longer available under the EMU.

9 See for an overview of the main instruments for policy coordination and surveillance: ECB (2014). See for historical evolution Molle (2006).

10 The proposals have been made by the heads of the EU executive institutions; they are discussed in detail in Begg et al. (2014, chapter 5).

11 See: e.g. Epstein (2014).

12 See for the illusion of cohesion that his created Fernandez-Villaverde et al. (2013).

13 See for development of the policy Bachtler et al. (2013) and Molle $(2007,2015)$.

14 The 2020 forecast figures (right hand column of Table 1) have been constructed in two stages. The 2015 figures have been taken from the forecast of the European Commission for each member country (EC 2014b). The 2015-2020 evolution has been forecast using the average longer term growth forecast for each member country made the IMF (2014) and the OECD (2012a,b). These forecasts take into account a large number of factors, but seem in general to assume that the factors determining the dynamics of each of the member countries are fairly stable over the long-term.

15 See Barca (2009), EC (2010), Barca et al. (2012), McCann (2015) and EC (2014c). See for further information on this new integrated policy framework for cohesion, Europe 2020 and Macro policy (European semester) Molle (2015) for further details and for an application to the largest V4 country: Ambroziak (2014).

16 See Camagni and Capello (2014). Similar considerations are voiced in EBRD (2013). See for further considerations that can lead to a failure of countries to stand up to challenges: Acemoglu and Robinson (2012) and Fukuyama (2014).

17 For evidence on the need to go along this way and the modalities of a possible implementation see: Molle (2012).

\section{References}

Acemoglu, D., Robinson, J. (2012), Why nations fail; the origins of power, prosperity and poverty, Crown Publishers, Carmarthan.

Ambroziak, A. (ed.) (2014), New cohesion policy of the European Union in Poland, Springer, Berlin.

Annoni, P., Dijkstra, L. (2013), EU Regional Competitiveness Index 2013, Joint Research Centre Scientific and Policy Reports: Luxembourg: Publications Office of the European Union.

Athanasoglou, S., Dijkstra, L. (2014), Europe 2020 regional index, JRC Science and Policy Reports, retrieved from: http://infoeuropa.eurocid.pt/files/database/000061001-000062000/000061431.pdf

Bachtler, J., Mendez, C., Wishlade, F. (2013), EU cohesion policy and European integration; The dynamics of EU budget and regional policy reform, Aldershot, Ashgate.

Barca, F. (2009), An agenda for a reformed cohesion policy; a place based approach to meeting European Union challenges and expectations, Report to DG Regio, Brussels.

Barca, F., McCann, Ph., Rodriguez-Pose, A. (2012), The case for regional development intervention; place based versus place neutral approaches, Journal of Regional Science, 52(1), pp. 134-152.

Begg, I., Macchiarelli, C., Bachtler, J., Mendez, C.,Wishlade, F. (2014), European Economic Governance and Cohesion Policy, Study for the European Parliament, IP/B/REGI/IC/2013-086.

Bristow, G. (2010), Critical reflections on regional competitiveness, theory, policy practice, Routledge, New York. 
Camagni, R. (2002), On the concept of territorial competitiveness, sound or misleading? Urban Studies, 39, pp. 2395-2411.

Camagni, R., Capello, R. (2014), Rationale and design of EU cohesion policies in a period of crisis, Regional Science Policy and Practice, DOI:10.1111/rsp3.12047

EBRD (2013), Transition Report; (convergence at risk), retrieved from: tr.ebrd.com

EC (2010), Regional Policy; an integrated approach; Panorama Inforegio, 34.

EC (2014a), European Competitiveness Report 2014.

EC (2014b), European Economic Forecast, Winter 2014, European Economy, 2/2014.

EC (2014c), Investment for jobs and growth; Promoting development and good governance in EU regions and cities, Sixth report on economic, social and territorial cohesion, Brussels.

ECB (2014), EMU policy framework, retrieved from https://ecb.europa.eu/ecb/tasks/europe/emu/html/index. en.html

EIU (2013), Hot spots 2025, benchmarking the future competitiveness of cities, CITI, London.

Epstein, R. (2014), Overcoming 'Economic Backwardness' in the European Union, Journal of Common Market Studies, 52(1), pp. 17-34.

Fernandez-Villaverde, J., Garicano, L., Santos, T. (2013), Political credit cycles; the case of the Eurozone, Journal of Economic Perspectives, 27(3), pp. 145-166.

Fukuyama, F. (2014), Political order and political decay, Profile Books, London.

IMF (2014), World Economic Outlook, available from the IMF website.

Kitson, M., Martin, R., Tyler, P. (2004), Regional competitiveness; an elusive yet key concept? Regional Studies, 38(9), pp. 991-999.

Martin, R., Kitson, M.,Tyler, P. (eds.) (2012), Regional competitiveness, Routledge, London and New York.

McCann, Ph. (2015), The regional and urban policy of the European Union, Cohesion, results orientation and smart specialization, Edward Elgar, Cheltenham.

Molle, W. (2006), The Economics of European Integration: Theory, Practice, Policy, $5^{\text {th }}$ ed., Ashgate, Aldershot.

Molle, W. (2007), European Cohesion Policy, Routledge, Abingdon.

Molle, W. (2011), European Economic Governance; the quest for consistency and effectiveness, Abingdon, Routledge.

Molle, W. (2012), Competitiveness, EMU and cohesion; Conditions for an effective post crisis EU policy, in: Latoszek, E. et al. (eds.) European integration process in the new regional and global setting, Warsaw University Press, Warsaw, pp. 233-267.

Molle, W. (2015), Cohesion and Growth; Theory and practice of European policy making, Routledge, London.

Musgrave, R.A., Musgrave, P. (1989), Public finance in theory and practice, McGraw Hill, New York.

OECD (2010), Economic surveys; euro area, Paris.

OECD (2012a), Economic Outlook 2012/1 (medium and long term forecast), Paris.

OECD (2012b), Looking to 2060; Long term growth prospects for the world, Economic Policy Papers, 3.

WEF (2014), The Europe 2020 competitiveness report, Building a more competitive Europe, World Economic Forum, Geneva. 